\title{
White Adipose Tissue: Storage and Effector Site for Environmental Pollutants
}

\author{
D. MÜLLEROVÁ ${ }^{1}$, J. KOPECKÝ ${ }^{2}$ \\ ${ }^{1}$ Institute of Public Health, Medical Faculty in Pilsen, Charles University, Pilsen and ${ }^{2}$ Department \\ of Adipose Tissue Biology, Institute of Physiology, Academy of Sciences of the Czech Republic, \\ v. v. i., Prague, Czech Republic \\ Received May 12, 2006 \\ Accepted June 27, 2006 \\ On-line available August 22, 2006
}

\begin{abstract}
Summary
White adipose tissue (WAT) represents a reservoir of lipophilic environmental pollutants, especially of those which are resistant to biological and chemical degradation - so-called persistent organic pollutants (POPs). Large amounts of different congeners and isomers of these compounds exhibit a variety of adverse biological effects. Interactions among different classes of compounds, frequently with opposing effects, complicate hazard evaluation and risk assessment. WAT is the key organ for energy homeostasis and it also releases metabolites into the circulation and adipokines with systemic effects on insulin sensitivity and fuel partitioning in muscles and other tissues. Its beneficial role is lost in obesity when excessive accumulation of WAT contributes to severe diseases, such as diabetes. POPs may crossroad or modulate the effect of endogenous ligands of nuclear transcription factors, participating in differentiation, metabolism and the secretory function of adipocytes. These mechanisms include, most importantly: i) endocrine disrupting potency of POPs' mixtures on androgen, estrogen or thyroid hormone metabolism/functions in WAT, ii) interference of dioxinlike chemicals with retinoic acid homeostasis, where impact on retinoid receptors is expected, and iii) interaction with transcriptional activity of peroxisome proliferator-activated receptors is likely. Thus, the accumulation and action of POPs in WAT represents a unitary mechanism explaining, at least in part, the effects of POPs in the whole organism. By modulating WAT differentiation, metabolism and function, the POPs could affect not only the physiological role of WAT, but they may also influence the development of obesity-associated diseases.
\end{abstract}

\section{Key words}

White adipose tissue $\bullet$ Organic pollutants $\bullet$ Endocrine disruption $\bullet$ Adipokines

\section{Introduction}

Even in a lean person, white adipose tissue (WAT) represents about 15 to $25 \%$ of body weight, and this percentage can increase by more than $50 \%$ in cases of morbidly obese patients. Since about $70 \%$ of the mass of WAT is formed by lipids, this tissue represents a major reservoir for many different lipophilic contaminants (Covaci et al. 2002). Most of them are persistent organic pollutants (POPs) which are also accumulated in higher 
trophic levels of the food chain. Thus food, especially fatty fish, meat and milk products, is the main source of human exposure to POPs. The variability of the stored amount of particular POPs in WAT, which can range over several orders of magnitude (Smeds and Saukko 2001), depends on dietary exposure and on individual disposition to store these substances. It is determined by the size of WAT and by changes in adiposity in response to energy homeostasis. Weight loss results in an increase of their concentration in reduced WAT (Jandacek et al. 2005) and their elimination rate is consequently decreased significantly with increasing body fat content (Michalek and Tripathi 1999).

\section{WAT and its function}

\section{Origin and metabolic function of the tissue}

For a long time WAT, derived from the mesenchyme, has been considered to be only a passive organ for storage of accumulated energy. Although metabolic processes in WAT are responsible for only a small (5-10 \%) fraction of total energy expenditure, WAT metabolism contributes to the control of body fat content (Kopecký et al. 2004) in cooperation with the liver and muscles, and functions as a buffer for fatty acid concentrations in the plasma during postabsorptional and fasting periods and prevents development of metabolic disorders. On the other hand, excessive accumulation of adipose tissue in obesity contributes to the development of severe diseases such as diabetes.

\section{WAT as an endocrine organ}

WAT metabolism is regulated by sympathetic innervation and by many hormones, like insulin, catecholamines, thyroid and steroid hormones. It is becoming increasingly apparent that WAT is a major endocrine organ in the body. It secretes many cytokines (adipokines like leptin, adiponectin, and visfatin, resistin, the tumor necrosis factor-alpha and many other molecules), which act in a paracrine manner and also as regulators of metabolism in other tissues. They affect body weight, insulin sensitivity or resistance, substrate partitioning, inflammation, fibrinolysis, atherogenesis and blood pressure.

\section{Transcriptional control of WAT differentiation and} function

Proliferation of precursor cells and their differentiation into mature adipocytes is under the control of several transcription nuclear factors with peroxisome proliferator-activated receptor (PPAR) gamma representing one of the key regulatory elements. Its activation by various ligands (such as fatty acids and eicosanoids) initiates permissive heterodimerization with the cis retinoid acid (RA) liganded retinoid $\mathrm{X}$ receptor (RXR). This complex binds to PPAR-responsive elements in the promoters of target genes and, with the help of various coactivators (like PPAR gamma coactivator-1, PGC-1), sets in the run the transcription process promoting adipocyte differentiation. The level of PPAR gamma protein peaks soon after differentiation and remains high in mature adipocytes. Thus PPAR gamma, together with other members of the PPAR family, which are expressed to a lower extent in WAT (PPAR alpha, beta/delta), functions as a cellular sensor for nutritional fatty acids which, in mature adipocytes, is capable of transducing metabolic signals into the transcriptional control of genes involved in insulin signaling, and glucose and fatty acid metabolism. This complex transcriptional machinery also results in a change of adipokine production, specifically in an increase of adiponectin (Iwaki et al. 2003) and a decrease of resistin, C-reactive protein secretion and soluble tumor necrosis factor alpha-receptor 2 expression (Samaha et al. 2005).

RA receptors (RARs), responsive to both alltrans RA (tRA) and to 9-cis RA, and RXRs responsive only to 9-cis RA, are highly expressed in WAT. RA as ligands to RARs affect the transcription of genes containing RA response elements along the RAR signalling pathway. Liganded RXR is, apart from PPARs, a common binding partner for a subgroup of other nuclear receptors expressed in WAT and creates functional heterodimers with them (Schulman and Mangelsdorf 2005). It is speculated that retinoids affect WAT development and function as physiological regulators. It was shown that adipogenic capacity is really increased by a vitamin A-deficient diet, where hypertrophy of WAT depots correlated with enhanced PPAR gamma 2 expression and RA treatment even reduced adiposity in some circumstances (Ribot et al. 2001). RA therapy lowered tissue expression and serum levels of resistin and improved glucose tolerance (Felipe et al. 2004).

Aryl hydrocarbon receptor (AhR) is also a ligandinducible transcription factor, which is expressed in WAT (Yoshinari et al. 2004), playing an important role in the programming of cell cycling and in the expression of genes required for detoxification of foreign compounds. Negative regulation of adipose differentiation by AhR was assumed. 


\section{Classification of POPs}

At present there are five main groups of POPs considered, which may be stored in human WAT: i) organochlorine pesticides; ii) polychlorinated biphenyls (PCBs); iii) dioxins, like polychlorinated dibenzo-pdioxins and dibenzofurans (PCDDs/Fs); iv) some polybrominated flame retardants (BFRs), and v) other unclassified pollutants, including e.g. phthalate esters. The first three groups are named collectively as organochlorine compounds.

Organochlorine pesticides have been released into the environment and for many years used as biocides. Although they were banned in the late seventies in most countries some of their residues, especially 2,2bis(4-chlorophenyl)-1,1-dichloroethene (DDE) - the metabolite of 2,2-bis(4-chlorophenyl)-1,1,1-trichloroethane (DDT), and hexachlorobenzene, are still highly widespread in the environment and in human WAT (Smeds and Saukko 2001).

PCBs, used to a great extent in diverse technical application until the 1970s (Safe 1994), can be divided into 'non-dioxin-like and 'dioxin-like' congeners, which have the ability to act as AhR agonists. Most frequently found congeners in WAT are, according to IUPAC nomenclature, as follows - No. PCB 153, 138, 180, 170, 118, 156. PCBs show neurotoxic, teratogenic and carcinogenic effects.

Dioxins are widespread, highly toxic pollutants, entering the environment mainly via improper combustion processes. From the 210 different congeners of PCDD/Fs there are $29 \mathrm{PCDD} / \mathrm{Fs}$ and PCBs congeners, assigned as dioxin-like substances that, according to WHO, have a similar chemical structure and toxicological properties as the most toxic congener from dioxines 2,3,7,8-tetrachlorodibenzo-p-dioxin (TCDD). Developmental toxicity, immune effects, endometriosis and cancer are considered as critical effects of dioxins. Diabetes and cardiovascular diseases are other reported effects of dioxins in humans (EFSA 2004). The poisoning with dioxin is associated with a wasting syndrome characterized by drastic weight loss and skin lesions such as chloracne and hyperpigmentation. In this case the brown adipose tissue is supposed to be one of primary targets for TCDD toxicity and its destruction in animals using sublethal doses of TCDD was documented (Rozman et al. 1986).

BFRs have routinely been added to consumer products with the aim of reducing fire-related injury and property damage. There is evidence of an increasing contamination of the environment and humans over the past 20 years.

Phthalate esters are widely used as plasticizers in the manufacture of products made of polyvinyl chloride, including medical bags and food packing. Di(2-ethylhexyl)phthalate (DEHP) is the most important phthalate ester in commercial use. DEHP and related plasticizers are not covalently bound to plastics and readily leak into the environment. The potential for human exposure by oral, dermal, inhalation and intravenous means is high. Exposure to phthalate esters results in developmental and reproductive organ toxicities and might induce accumulation of lipids in adipocytes (Maloney and Waxman 1999; see below).

From adipose tissue has been also isolated bisphenol A diglycidyl ether (BADGE) (Wright et al. 2000) which is a commercially produced chemical with industrial application, mainly used in the production of polycarbonate and industrial plastics.

\section{Mechanisms of adverse effects of POPs}

\section{Endocrine disrupting potency of POPS}

Organochlorine pesticides, together with PCBs and PCDD/Fs, rank among "endocrine disruptors", which are able to impair normal embryonic development and disrupt reproductive functions in adulthood. They especially influence estrogen- or androgen-mediated processes, through mimicking or antagonizing their physiological functions. The effect of organochlorines on different modulation of estrogen-regulated genes is tissue- and compound-specific and is dependent on the energetic balance which induces changes of WAT size (Villa et al. 2004). Expression of estrogen and androgen receptors in WAT (see also above) is more clearly dependent on adipose depot location rather than on sex, when visceral depots show overall higher densities (Rodriguez-Cuenca et al. 2005). POPs may bind these receptors and interfere with hormones, and consequently influence cellular energy metabolism and fat deposition. Reduced effects of estrogens in WAT (Kamei et al. 2005) demonstrated in mice after ovariectomy, were consistent with the obese phenotype. Furthermore, they were associated with the lower levels of nuclear receptors and co-factors involved in energy expenditure, estrogenrelated receptor 1, PPARs (alpha; delta), and PGC-1, and in lipogenesis (PPAR gamma and sterol response element binding protein, see also above). Interestingly, 
upregulation of mitochondrial biogenesis and betaoxidation by dietary n-3 polyunsaturated fatty acids in WAT is associated with the prevention of insulin resistance (Flachs et al. 2005).

Androgen-disrupting potency of organochlorine pesticides is discussed in connection with DDT, DDE, dieldrin, methoxychlor, and lindan. At present, DDE is the most prevalent metabolite of DDT in WAT, which has been demonstrated to be an androgen receptor antagonist (Kelce et al. 1995), similarly to PCB 118, 138 and 153 (Schrader and Cooke 2003). Pitteloud et al. (2005) showed in men a positive correlation between insulin sensitivity and serum testosterone levels, which were further correlated with mitochondrial functions in muscles. According to Petersen et al. (2003) mitochondrial dysfunction in muscles contributes to insulin resistance of skeletal muscles in the elderly. On the other hand, Imbeault et al. (2002) suggested that the weight loss-induced increase in plasma organochlorine pollutant levels may reduce skeletal muscle oxidative metabolism in men, but not in women.

Another site of the possible influence of POPs could be localized on estrogen biosynthesis in WAT, which depends on a circulating source of androgenic precursors such as testosterone and its catalysis by aromatase cytochrome P450. A defect of brain aromatase has been described after PCB treatment (Hany et. al. 1999). A disorder of the phenotype of local estrogen biosynthesis, demonstrated using aromatase knocked-out mice, is characterized by a metabolic syndrome with insulin resistance, truncal obesity and hepatic steatosis (Simpson et al. 2005).

\section{Dioxin effect of $P C D D / F$ and dioxin-like PCBs}

Dioxins are toxic and affect gene expression, especially in the liver and probably also in WAT (see also above), through the activation of nuclear receptors or AhR (Mimura et al.2003). Through the latter mechanism, dioxins influence phase I drug-metabolizing- and phase II- enzymes with a broad spectrum of consequences. Furthermore, there are several AhR-regulated genes coding the enzymes affecting RA levels. This altered expression of genes leads to impaired RA homeostasis with the consequence of disturbances in the retinoid signaling system. The effect of long-term, low-dose exposure to dioxins is the reduction of hepatic retinyl ester levels and species-related reduction/excess of RA in extrahepatic tissues (Nilsson and Hakansson 2002). Shimba et al. (1998) demonstrated that treatment of 3T3-
L1 fibroblast cells with TCDD suppresses their differentiation into adipocyte cells (probably via AhR). Because of transcriptional down-regulation of AhR gene with ongoing adipose differentiation these authors assume a loss of the functional response of matured adipocytes to TCDD (Shimba et al. 2003). Kern et al. (2002) have also shown a decrease of lipid accumulation and affected glucose transport in adipocyte cells of 3T3F442 mice after TCDD treatment during the differentiation process. However, an increase of tumor necrosis factor alfa secretion in adipocyte cells after TCDD treatment was demonstrated even after the cells had fully differentiated. It suggests a participation of another transcription mechanism. Based on the results of Hoegberg et al. (2005) with RXR beta 2 - knocked-out mice, not showing disturbances in retinoid storage and metabolism after TCDD treatment, it could be supposed that RXR beta 2 also plays an important role in TCDDinduced retinoid disruption.

Epidemiological studies identified a link between dioxins and diabetes which supposedly results from the inhibition of the PPAR gamma/RXR signaling pathway by dioxins (Remillard and Bunce 1998). The presence of TCDD in tissues may change the ratio between all trans RA and cis RA concentrations and in this way modulate the prevailing transcriptional pathway in retinoid signaling using RAR or RXR receptors with different results. Possible perturbation of transcriptional activity of PPAR gamma through to dioxin interference with retinoid turnover and metabolism and decrease of $\mathrm{cis}$ RA level comes subsequently into play.

\section{Other mechanisms}

Interesting is the function of another synthetic compound BADGE, a chemical sometimes detected in food and tissues, coming from plastic materials. This was the first PPAR gamma antagonist identified (Wright et al. 2000). Since it has been described not only to be PPAR gamma antagonist in adipogenic cells, which can antagonize the ability of PPAR gamma ligands to activate the transcriptional and adipogenic action of this receptor, but also as a PPAR gamma agonist in macrophage-like cells, which can increase a promotor activity of the PPAR gamma-luciferase reporter gene and also suppress lipopolysaccaride-induced TNF alpha production (Nakamuta et al. 2002).

Maloney and Waxman (1999) demonstrated transcriptional activity of human and mouse PPARs to be stimulated by phthalate monoesters that are formed from 
environmental phthalates by esterase in the gut and other tissues. The most important in this respect is mono(2ethylhexyl)phthalate, a DEHP metabolite. While stimulation of PPAR alpha in liver induces liver cancer in rodents, stimulation of PPAR gamma may result in the activation of target genes in WAT. It could be speculated that a high contamination by phthalates of our environment contributes to obesity epidemics.

\section{Conclusions}

Hydrophobic environmental contaminants, POPs, stored in WAT may modulate the activity of key transcription factors engaged in control of differentiation, metabolism and the secretory function of adipocytes. Thus, POPs may act as ligands of AhR, PPARs, RAR/RXR, estrogen and androgen receptors. By modulating WAT differentiation, metabolism and function, the environmental contaminants could affect not only the physiological role of WAT but may also influence the development of obesity-associated diseases such as diabetes. Moreover, since plasma levels of POPs increase during rapid weight loss, and some POPs induce adiposity by direct interactions with the transcription machinery in adipocytes, POPs may contribute to weight cycling with the known "yo-yo" effects. A unitary concept for a mechanism of a large array of POPs, based on the accumulation of POPs in the dynamic reservoir of WAT and modulation of the adipocyte phenotype by these compounds, deserves further studies.

\section{Acknowledgements}

Supported by a grant MSM 0021620819 "Replacement of and support to some vital organs" Charles University, Medical School and Teaching Hospital Plzen, Czech Republic.

\begin{abstract}
Abbreviations
AhR (arylhydrocarbon receptor), BFRs (brominated flame retardants), BDEs (bromodiphenyl ethers), DDE (2,2-bis(4-chlorophenyl)-1,1-dichloroethene), DEHP (di(2-ethylhexyl)phthalate), DDT (2,2-bis(4-chlorophenyl)-1,1,1-trichloroethane), PCBs (polychlorinated biphenyls), PCDDs/Fs (polychlorinated dibenzo-pdioxins and polychlorinated dibenzofurans), PGC-1 (peroxisome proliferator-activated receptor- $\gamma$ coactivator, POPs (persistent organic pollutants), PPAR (peroxisome proliferator activated receptor), RA retinoic acid, RAR (retinoic acid receptor), RXR (retinoid $\mathrm{X}$ receptor), TCDD (2,3,7,8-tetrachlorodibenzo-p-dioxin), WAT white adipose tissue
\end{abstract}

\section{References}

COVACI A, BOER J, Ryan JJ, VOORSPOELS S, SCHEPENS P: Distribution of organobrominated and organochlorinated contaminants in Belgian human adipose tissue. Environm Res Section 88: 210 -218, 2002.

EFSA: Dioxins. Methodologies and principles for setting tolerable intake levels for dioxins, furans and dioxin-like PCBs. EFSA Scientific Colloquium Summary Report. Brussels, 2004, p 130.

FELIPE F, BONET ML, RIBOT J, PALOU A: Modulation of resistin expression by retinoic acid and vitamin A status. Diabetes 53: 882-889, 2004.

FLACHS P, HORÁKOVÁ O, BRAUNER P, ROSSMEISL M, PECINA P, FRANSSEN-VAN HAL N, RŮŽIČKOVÁ J, ŠPONAROVÁ J, DRAHOTA Z, VLČEK C, KEIJER J, HOUŠTĚK J, KOPECKÝ J: Polyunsaturated fatty acids of marine origin upregulate mitochondrial biogenesis and induce beta-oxidation in white fat. Diabetologia 48: 2365-2375, 2005.

HANY J, LILIENTHAL H, SARASIN A, ROTH-HARER A, FASTABEND A, DUNEMANN L, LICHTENSTEIGER W, WINNEKE G: Developmental exposure of rats to a reconstituted PCB mixture or aroclor 1254: Effects on organ weights, aromatase activity, sex hormone levels, and sweet preference behavior. Toxicol Appl Pharmacol 158: 241-243, 1999.

HOEGBERG P, SCHMIDT CK, FLETCHER N, NILSSON CHB, TROSSVIK CH, SCHUUR AG, BROUWER A, NAU H, GHYSELINCK NB, CHAMBON P, HAKANSSON H: Retinoid status and responsiveness to retinoid binding protein or retinoid receptor forms. Chem Biol Interact 156: 25-39, 2005.

IMBEAULT P, TREMBLAY A, SIMONEAU J-A, JOANISSE DR: Weight loss-induced rise in plasma pollutant is associated with reduced skeletal muscle oxidative capacity. Am J Physiol 282: E574-E579, 2002. 
IWAKI M, MATSUDA M, MAEDA N, FUNAHASHI T, MATSUZAWA Y, MAKISHIMA M, SHIMOMURA I: Effects of rosiglitazone on lipids, adipokines, and inflammatory markers in nondiabetic patients with low highdensity lipoprotein cholesterol and metabolic syndrome. Diabetes 52: 1655-63, 2003.

JANDACEK RJ, ANDERSON N, LIU M, ZHENG S, YANG Q, TSO P: Effects of yo-yo diet, caloric restriction, and olestra on tissue distribution of hexachlorobenzene. Am J Physiol 288: G292-G299, 2005.

KAMEI Y, SUZUKI M, MIYAZAKI H, TSUBOYAMA-KASAOKA N, WU J, ISHIMI Y, EZAKI O: Ovariectomy in mice decreases lipid metabolism-related gene expression in adipose tissue and skeletal muscle with increased body fat. J Nutr Sci Vitam 51: 110-117, 2005.

KELCE WR, STONE CH R, LAWS SC, GRAY LE, KEMPPAINEN JA, WILSON EM: Persistent DDT metabolite p,p'-DDE is a potent androgen receptor antagonist. Nature 375: 581-585, 1995.

KERN PA, DICKER-BROWN A, SAID ST, KENNEDY R, FONSECA VA: The stimulation of tumor necrosis factor and inhibition of glucose transport and lipoprotein lipase in adipose cells by 2,3,7,8-tetrachlorodibenzo-pdioxin. Metabolism 51: 65-68, 2002.

KOPECKÝ J, ROSSMEISL M, FLACHS P, BRAUNER P, ŠPONAROVÁ J, MATĚJKOVÁ O, PRAŽÁK T, RŮŽIČKOVÁ J, BARDOVÁ K, KUDA O: Energy metabolism of adipose tissue - physiological aspects and target in obesity treatment. Physiol Res $\mathbf{5 3}$ (Suppl 1): S225-S232, 2004.

MALONEY EJ, WAXMAN DJ: Trans-activation of PPAR $\alpha$ and PPAR $\gamma$ by structuraly diverse environmental chemicals. Toxicol Appl Pharmacol 161: 209-218, 1999.

MICHALEK JE, TRIPATHI RC: Pharmacokinetics of TCDD in veterans of operation ranch hand: 15-year follow-up. J Toxicol Environ Health 57: 369-378, 1999.

MIMURA J, FUJII-KURIYAMA Y: Functional role of AhR in the expression of toxic effects by TCDD. Biochem Biophys Acta 1619: 263-268, 2003.

NAKAMUTA M, ENJOJI M, UCHIMURA K, OHTA S, SUGIMOTO R, KOTOH K, KATO M, IRIE T, MUTA T, NAWATA H: Bisphenol A diglycidyl ether (BADGE) suppresses tumour necrosis factor-alpha production as a PPAR gamma agonist in the murine macrophage-like cell line, RAW 264.7. Cell Biol Int 26: 235-241, 2002.

NILSSON CB, HAKANSSON H: The retinoic signaling system - a target in dioxin toxicity. Crit Rev Toxicol 32: 211$232,2002$.

PETERSEN KF, BEFROY D, DUFOUR S, DZIURA J, ARIYAN C, ROTHMAN DL, DIPIETRO L, CLINE GW, SHULMAN GI: Mitochondrial dysfunction in the elderly: possible role in insulin resistance. Science 16: 1140$1142,2003$.

PITTELOUD N, MOOTHA VK, DWYER AA, HARDIN M, LEE H, ERIKSSON KF, TRIPATHY D, YIALAMAS M, GROOP L, ELAHI D, HAYES FJ: Relationship between testosterone levels, insulin sensitivity, and mitochondrial function in men. Diabetes Care 28: 1636-1642, 2005.

REMILLARD RB, BUNCE NJ: Linking dioxins to diabetes: epidemiology and biology plausibility. Environ Health Perspect 110: 853-867, 1998.

RIBOT J, FELIPE F, BONET ML, PALOU A: Changes of adiposity in response to vitamin A status correlate with changes of PPAR gamma 2 expression. Obes Res 9: 500-509, 2001.

RODRIGUEZ-CUENCA S, MONJO M, PROENZA AM, ROCA P. Depot differences in steroid receptor expression in adipose tissue: possible role of the local steroid milieu. Am J Physiol 288: E200-E207, 2005.

ROZMAN K, PEREIRA D, IATROPOULOS MJ: Histopathology of interscapular brown adipose tissue, thyroid, and pancreas in 2,3,7,8-tetrachlorodibenzo-p-dioxin (TCDD)-treated rats. Toxicol Appl Pharmacol. 82: 551-559, 1986.

SAFE SH. Polychlorinated biphenyls: (PCBs). Environmental impact, biochemical and toxic responses, and implications for risk assessment. Crit Rev Toxicol 24: 87-149, 1994.

SAMAHA FF, SZAPARY PO, IQBAL N, WILLIAMS MM, BLOEDON LT, KOCHAR A, WOLFE ML, RADER DJ: Effects of rosiglitazone on lipids, adipokines, and inflammatory markers in nondiabetic patients with low highdensity lipoprotein cholesterol and metabolic syndrome. Arterioscler Thromb Vasc Biol 26: 624-630, 2006.

SCHRADER TJ, COOKE GM: Effects of Aroclors and individual PCB congeners on activation of the human androgen receptor in vitro. Reprod Toxicol. 17: 15-23, 2003. 
SCHULMAN AI, MANGELSDORF DJ: Retinoid X receptor heterodimers in the metabolic syndrome. $N$ Engl $J$ Med 353: 604-615, 2005.

SHIMBA S, TODOROKI K, AOYAG, T, TEZUKA M: Depletion of arylhydrocarbon receptor during adipose differentiation in 3T3-L1 cells. Biochem Biophys Res Commun 249: 131-137, 1998.

SHIMBA S, HAYASHI M, OHNO T, TEZUKA, M: Transcriptional regulation of the AhR gene during adipose differentiation. Biol Pharm Bull 26: 1266-1271, 2003.

SIMPSON ER, MISSO M, HEWITT KN, HILL RA, BOON WC, JONES ME, KOVACIC A, ZHOU J, CLYNE CD: Estrogen - the good, the bad, and the unexpected. Endocri Rev 26: 322-330, 2005.

SMEDS A, SAUKKO P: Identification and quantification of polychlorinated biphenyls (PCBs) and some endocrine disrupting pesticides in human adipose tissue from Finland. Chemosphere 44: 1463-1471, 2001.

VILLA R, BONETTI E, PENZA ML, LACOBELLO C, BUGARI G, BAILO M, PAROLINI O, APOSTOLI P, CAIMI L, CIANA P, MAGGI A, Di LORENZO D: Target-specific action of organochlorine compounds in reproductive and nonreproductive tissues of estrogen-reporter male mice. Toxicol Appl Pharmacol 201: 137$148,2004$.

WRIGHT HM, CLISH CB, MIKAMI T, HAUSER S, YANAGI K, HIRAMATSU R, SERHAN CH, SPEGELMAN B: A synthetic antagonist for the peroxisome proliferator-activated receptor gamma inhibits adipocyte differentiation. J Biol Chem 275: 1873-1877, 2000.

YOSHINARI K, SATO T, OKINO N, SUGATANI J, MIWA M: Expression and inducion of cytochromes P450 in rat white adipose tissue. J Pharmacol Exp Ther 10: 1124-1137, 2004.

\section{Corresponding author}

D. Mullerova, Institute of Public Health, Medical Faculty in Pilsen, Charles University, Lidicka 4, 30166 Pilsen, Czech

Republic. E-mail: dana.mullerova@lfp.cuni.cz 